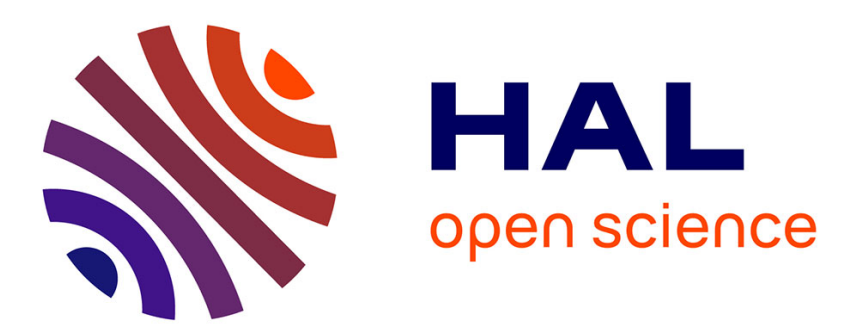

\title{
Analysis of the exceptionally warm December 2015 in France using flow analogues
}

\author{
Aglaé Jézéquel, Pascal Yiou, Sabine Radanovics, Robert Vautard
}

\section{To cite this version:}

Aglaé Jézéquel, Pascal Yiou, Sabine Radanovics, Robert Vautard. Analysis of the exceptionally warm December 2015 in France using flow analogues. Bulletin of the American Meteorological Society, 2017, 99 (1), pp.S76-S79. 10.1175/BAMS-D-17-0103.1 . hal-01631444

\section{HAL Id: hal-01631444 \\ https://hal.science/hal-01631444}

Submitted on 9 Nov 2017

HAL is a multi-disciplinary open access archive for the deposit and dissemination of scientific research documents, whether they are published or not. The documents may come from teaching and research institutions in France or abroad, or from public or private research centers.
L'archive ouverte pluridisciplinaire HAL, est destinée au dépôt et à la diffusion de documents scientifiques de niveau recherche, publiés ou non, émanant des établissements d'enseignement et de recherche français ou étrangers, des laboratoires publics ou privés. 

Laboratoire des Sciences du Climat et de l'Environnement, UMR8212 CEA-CNRS-UVSQ, IPSL and U Paris Saclay, Gif-sur-Yvette, France.

Capsule December 2015 in France was an extreme of circulation and temperature. Both circulation and climate change partly explain the $4^{\circ} \mathrm{C}$ anomaly. We found no link between climate change and

8 circulation.

The event

The December 2015 average temperature broke a record in France, with an anomaly of $+4.1^{\circ} \mathrm{C}$ (Fig. 1a) with respect to the $1949-2015$ climatology. The linear trend of average December temperature (in red in Fig. 1a) is not significant ( $p$-value $>0.05$ ), as regional temperature variability

14 is high in winter. Such a positive temperature anomaly has impacts on the vegetation cycle (the French press covered this topic in the daily newspaper Le Monde ${ }^{1}$ ). It also affects local economies, e.g. tourism in ski resorts. The temperature anomaly was concomitant with a zonal atmospheric circulation over Western Europe (Fig. 1b), directing mild subtropical air masses towards France. We found that the mean monthly SLP (sea level pressure) anomaly over the black box of Fig.1b is also

19 a record high for the NCEP reanalysis. Such a circulation type generally leads to warm temperatures overs France (Yiou and Nogaj, 2004).

In this paper we seek to address three questions: How much does the circulation anomaly

22 explain the temperature anomaly during December 2015 in France? What is the influence of climate 23 change on the occurrence of the circulation anomaly? How does the distribution of temperature 24 conditional to the atmospheric circulation evolve with climate change? We hence perform a 25 conditional attribution exercise (NAS, 2016, p. 30), with a circulation that is fixed to the 
observation of December 2015. This estimates the thermodynamic contribution of climate change

27 on the increase of temperature (Vautard et al., 2016; Yiou et al., 2017).

Flow analogues and the role of circulation

We evaluated the link between the SLP anomalies over the black box in Fig. 1b and temperature in

France using the method of flow analogues (e.g. Yiou et al. 2017). We considered the French national temperature index supplied by Météo France (Soubeyroux et al. 2016). This daily index is computed as the average of 30 stations distributed over France and starts in 1949. We use temperature anomalies with respect to a daily seasonal cycle obtained by spline smoothing (cf. Yiou et al., 2008). The circulation proxy is the SLP from the National Centers for Environmental Predictions (NCEP) reanalysis, between 1949 and 2015. For each day of December 2015 we identified the 30 best analogues of SLP (with a Euclidean distance) from 1949 to 2015 on the domain delimited by the black rectangle in Fig. 1b. Jézéquel et al. (2017) showed that the results on analogues are qualitatively insensitive to the number of analogues (between 5 and 30 analogues). We simulate daily sequences of SLP by randomly picking one of the 30 best analogues within the

41 NCEP dataset for each day. The repetition of this random selection (with replacements) builds an 42 ensemble of uchronic months. Those uchronic months reproduce the SLP anomaly of December 432015 (see Fig. S1a-d in Supplementary Material). We then compute monthly averages for December 44 of the national temperature index. We hence obtain uchronic French seasonal anomalies of temperature for December. We iterated this process $10^{4}$ times in order to produce uchronic probability distributions of monthly mean temperatures (see Jézéquel et al. 2017 for more details).

47 This uchronic distribution of temperatures represents the ensemble of temperatures that could have 48 been expected for the circulation observed in December 2015. We compared the uchronic 49 distribution of temperature anomalies to a distribution built from randomly picked December days. In Fig. 1c, the Control experiment corresponds to a monthly average of the daily temperature 
52 order to take into account the dependence between consecutive days in the Control distribution, we 53 calculated the monthly means using only every third day (Jézéquel et al. 2017).

We find that the SLP partly explains the monthly temperature anomaly in France during

December 2015 (Fig. 1c). The median of the uchronic temperature anomaly distribution is $1.3^{\circ} \mathrm{C}$,

i.e. $\sim 30 \%$ of the anomaly. The other $\sim 70 \%$ of the anomaly could be explained by other factors (e.g.

snow cover feedback). This positive anomaly demonstrates the link between the synoptic situation and the anomaly of temperature in France, and justifies the choice of a conditional attribution

\section{9 approach.}

$\underline{\text { Role of climate change }}$

In order to estimate the role of climate change we rely on the CESM1 model large ensemble,

CESM-LENS (Kay et al., 2015). We use 30 members for both surface temperature and SLP using historical runs between 1951 and 2005 and RCP8.5 between 2006 and 2100 . We reconstitute the French national temperature index from the surface temperature using the coordinates of the 30 stations used to calculate the index. Kay et al. (2015) showed that CESM-LENS reproduces reasonably well features of the Northern Hemisphere atmospheric circulation. An analysis of the SLP distances between those observed during December 2015 and CESM simulations indicates that they are not statistically different from the NCEP reanalysis (Fig.S1e in the Supplementary material). We hence consider that this model does not yield biases that prevent its use for the 71 purpose of this study.

We estimate the influence of climate change on the circulation pattern leading to December 2015 by computing the probability distributions of distances between SLP anomalies among all the December days in both NCEP and CESM and the closest day of December 2015 (Fig. 2a). We keep only the distances below the $5^{\text {th }}$ percentile of the distribution, in order to focus on the days with SLP anomalies closest to those observed in December 2015. For each December, we count the number 
prevailed in December 2015 became more frequent with time, then a trend should be detected in this number of days. We detect no such trend. Therefore it is not possible to conclude there is an impact of climate change on the atmospheric circulation itself.

We then estimate the temperature anomaly for a similar event in terms of synoptic circulation without climate change, and in future climate change scenarios by computing analogues of circulation from different periods of observations and CESM simulations. We analyzed the uchronic temperature anomalies constructed with analogues of the December 2015 flows from two time periods of the NCEP dataset. We compared an early subset of 33 years (1949-1981) to a more recent one (1982-2014). The two gold boxplots in Fig. 2b represent those two experiments. We detected a difference of $0.4{ }^{\circ} \mathrm{C}$ between the two distributions, in contrast with the monthly temperature trend for 1949-2015 displayed in Fig. 1c, which is not significant. However, it is not possible to attribute this difference of temperature to climate change, as it could also relate to interdecadal variability, especially for very small subsets of 33 years, whose length was imposed by the NCEP reanalysis length.

In order to study the relative influences of climate change and variability, we rely on CESM-

LENS. We study three periods of 50 years: 1951-2000, 2001-2050, and 2051-2100. Using 30 members, we have 1500 years of data for each sub-period from which we can calculate the analogues (which correctly represent the observed SLP anomaly as displayed in the supplementary material Fig. S1a-d). This reduces the uncertainty related to the quality of the analogues we picked. The three pink boxplots in Fig. $2 \mathrm{~b}$ represent the uchronic distributions for SLP analogues picked from CESM-LENS. The three red boxplots represent the control distributions for the same sub-

99 periods. We observe that the December 2015 anomaly of temperature was never reached before 100 2000. It is still not reached for 2001-2050 under the RCP8.5 scenario. For the second half of the 10121 st century the temperature anomaly is expected to exceed $4^{\circ} \mathrm{C}$ for the same synoptic situation. 102 The observed anomaly is still warmer than the median of the control distribution. A caveat of this study is that we only used one model, which could have biases especially in the future. 
The month of December 2015 set a record temperature in France. The zonal circulation that 106 prevailed over Western Europe during the whole month accounts for $\sim 30 \%$ or $1.3^{\circ} \mathrm{C}$ of the 107 temperature anomaly. No trend was found in the atmospheric circulation patterns themselves (Fig. 108 2a). For this given circulation, our analysis shows that the observed temperature is never reached in 109 the second half of the 20th century (Fig. 2b), and the model is unable to reach it even during the 110 first half of the $21^{\text {st }}$ century. However, the December temperature observed in 2015 is projected to 111 be exceeded in the second half of the 21 st century under the same synoptic situation. Cattiaux et al. 112 (2010) found with a similar analysis that the cold winter of 2009/2010 would have been colder if 113 not for climate change. Our analysis of December 2015 is a warm counterpart to that study. We find 114 a $1.4^{\circ} \mathrm{C}$ difference between the median of the uchronic temperatures of the second half of the 20th 115 century and the first half of the 21 st century and an additional $1.9^{\circ} \mathrm{C}$ for the second half of the 21 st 116 century. We find approximately the same differences between Control distribution medians, which 117 means that the trend conditional to the circulation equals the unconditional trend.

Acknowledgements

120 PY, AJ and SR are supported by the ERC grant No. 338965-A2C2. This work is also supported by 121 the Copernicus EUCLEIA project No. 607085.

\section{$\underline{\text { References }}$}

125 Cattiaux, J., Vautard, R., Cassou, C., Yiou, P., Masson-Delmotte, V., \& Codron, F. (2010). Winter 1262010 in Europe: a cold extreme in a warming climate. Geophysical Research Letters, 37(20). doi:10.1029/2010GL044613

128 Jézéquel, A., Yiou P., Radanovics S. (2017, accepted). Role of circulation in European heatwaves using flow analogues. Climate Dynamics. doi: 10.1007/s00382-017-3667-0 
130 Kay, J.E., Deser, C., Phillips, A., Mai, A., Hannay, C., Strand, G., Arblaster, J.M., Bates, S.C., 131 Danabasoglu, G., Edwards, J. and Holland, M. (2015). The Community Earth System Model 132 (CESM) large ensemble project: A community resource for studying climate change in the presence 133 of internal climate variability. Bulletin of the American Meteorological Society, 96(8), pp.1333134 1349. doi:10.1175/BAMS-D-13-00255.1

135 Kalnay, E., Kanamitsu, M., Kistler, R., Collins, W., Deaven, D., Gandin, L., Iredell, M., Saha, S., 136 White, G., Woollen, J. and Zhu, Y. (1996). The NCEP/NCAR 40-year reanalysis project. Bulletin of 137 the American meteorological Society, 77(3), pp.437-471. doi: $10.1175 / 1520-$ $138 \quad \underline{0477(1996) 077<0437: T N Y R P>2.0 . C O ; 2}$

139 National Academies of Sciences, Engineering, and Medicine. 2016. Attribution of Extreme Weather 140 Events in the Context of Climate Change. Washington, DC: The National Academies Press. doi: $141 \quad 10.17226 / 21852$.

142 Soubeyroux, J. M., Ouzeau, G., Schneider, M., Cabanes, O., \& Kounkou-Arnaud, R. (2016), Les 143 vagues de chaleur en France: analyse de l'été 2015 et évolutions attendues en climat futur. 144 Rubrique: Climatologie. Doi:10.4267/2042/60704

145 Vautard R., P. Yiou, F. Otto, P. Stott, N. Christidis, G.J. van Oldenborgh and N. Schaller (2016). 146 Attribution of human-induced dynamical and thermodynamical contributions in extreme weather 147 events, Environ. Res. Lett. 11114009 doi:10.1088/1748-9326/11/11/114009

148 Yiou, P., and M. Nogaj (2004), Extreme climatic events and weather regimes over the North 149 Atlantic: When and where? Geophys. Res. Lett., 31, L07202, doi:10.1029/2003GL019119.

150 Yiou, P., K. Goubanova, Z. X Li., and M. Nogaj (2008), Weather regime dependence of extreme 151 value statistics for summer temperature and precipitation, Nonlin. Proc. Geophys., 15, 365-378.

152 Yiou, P., Jézéquel, A., Naveau, P., Otto, F. E. L., Vautard, R., and Vrac, M. (2017) A statistical 153 framework for conditional extreme event attribution, Adv. Stat. Clim. Meteorol. Oceanogr., 3, 1731, doi:10.5194/ascmo-3-17-2017. 
$157 \quad$ Figure caption list

158 Figure 1:

159 (a) Evolution of the French national temperature index for the month of December between 1949 160 and 2015. The red line is the (non significant) linear trend. (b) SLP anomalies for December 2015 161 relative to the 1949-2015 average of the NCEP Reanalysis I dataset (Kalnay et al. 1996). (c) 162 Comparison of uchronic monthly seasonal anomalies of the national index distribution for randomly 163 picked days (Control) and randomly picked analogues. The red line is the observed temperature 164 anomaly $\left(+4^{\circ} \mathrm{C}\right)$. The three lines composing the boxplots are respectively from bottom to top, the 165 25th (p25), median (p50) and 75th percentile (p75) of the uchronic temperature anomaly 166 distribution. The value of the upper whiskers is $\min (1.5 \times(\mathrm{p} 75-\mathrm{p} 25)+\mathrm{p} 50, \max ($ temperature 167 anomaly)). The value of the lower whiskers is its conjugate. The circles represent the values that are 168 outside of the whiskers.

169 Figure 2:

170 (a) Number of days per year with SLP distances below the $5^{\text {th }}$ percentile of the distribution of daily 171 distances to the closest December 2015 day. The boxplots show the dispersion of CESM ensemble 172 members. The blue lines-dots are the values for the NCEP reanalysis. The red line is the (non 173 significant) linear trend of the median of the CESM ensemble members. (b) Boxplots of the 174 distributions (respectively uchronic distributions) of anomalies of the national temperature index 175 relative to the observed climatology of this index between 1948 and 2015, in yellow (orange) using 176 NCEP and in red (pink) using CESM-LENS subsets. 
$180 \quad \underline{\text { Figures }}$

181 Figure 1:

182 (a)

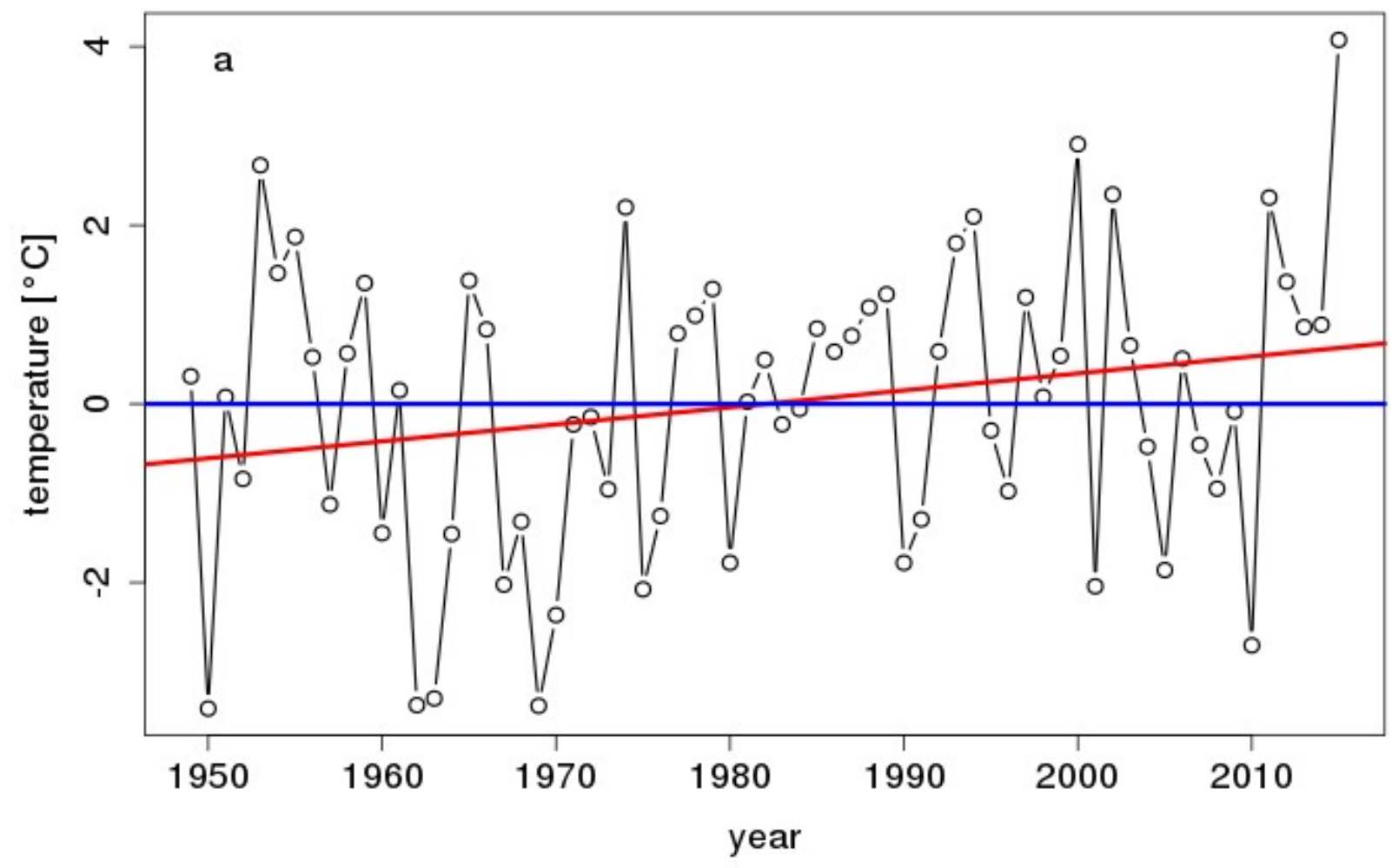

184

185

186 
187 (b)

\section{SLP anomalies [Pa]}

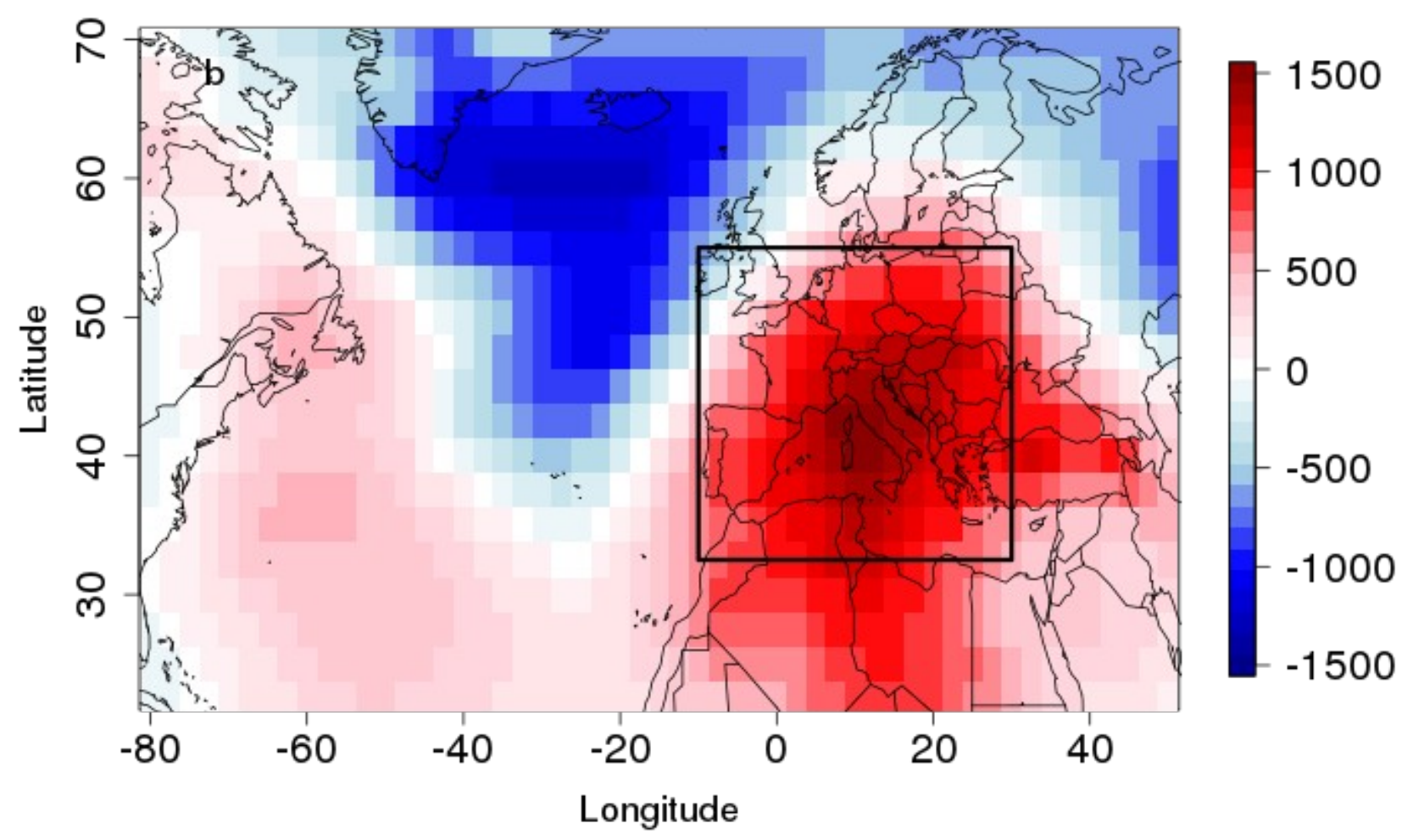

$189 \quad$ (c) 


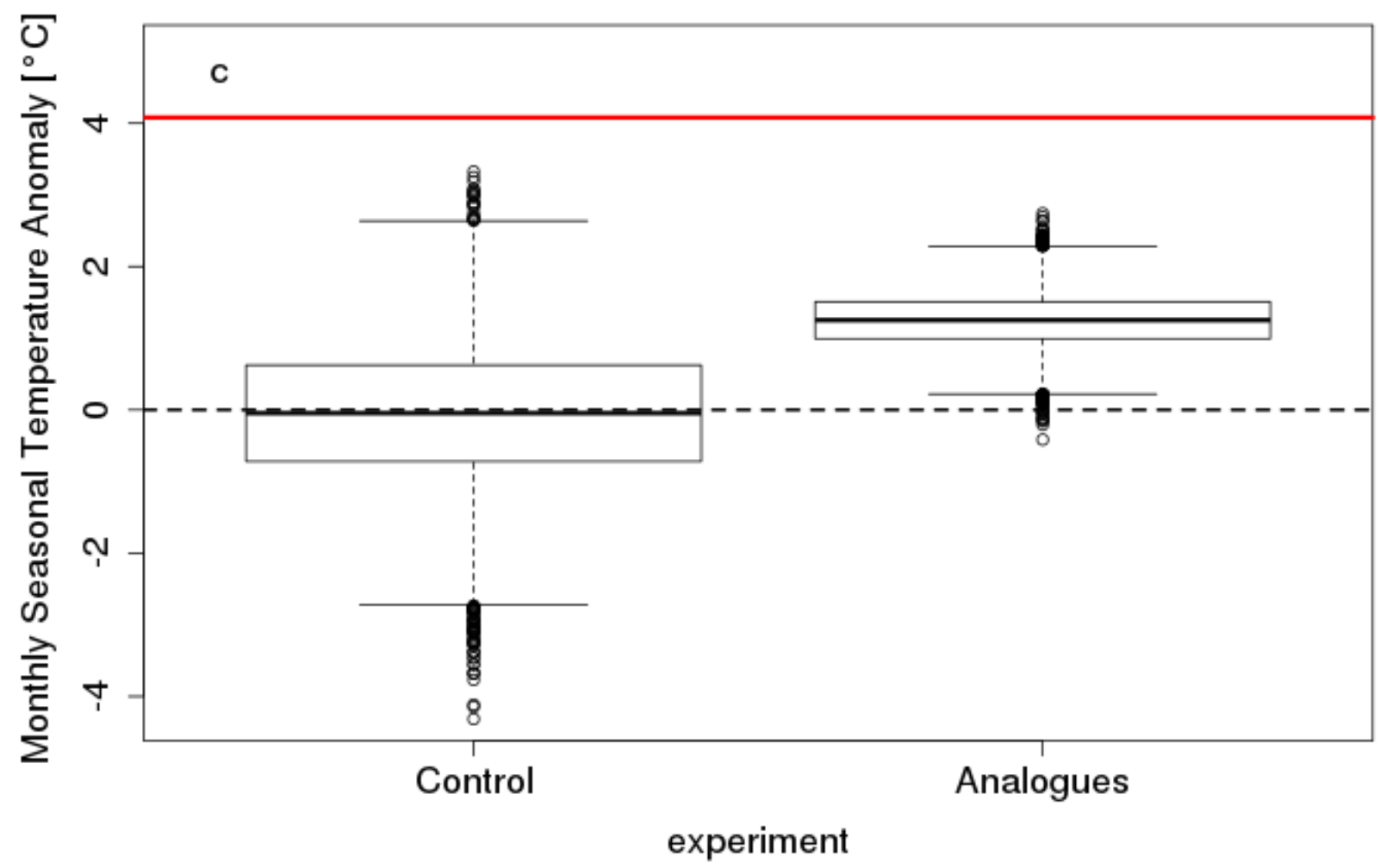

191 
Figure 2:

193 (a)

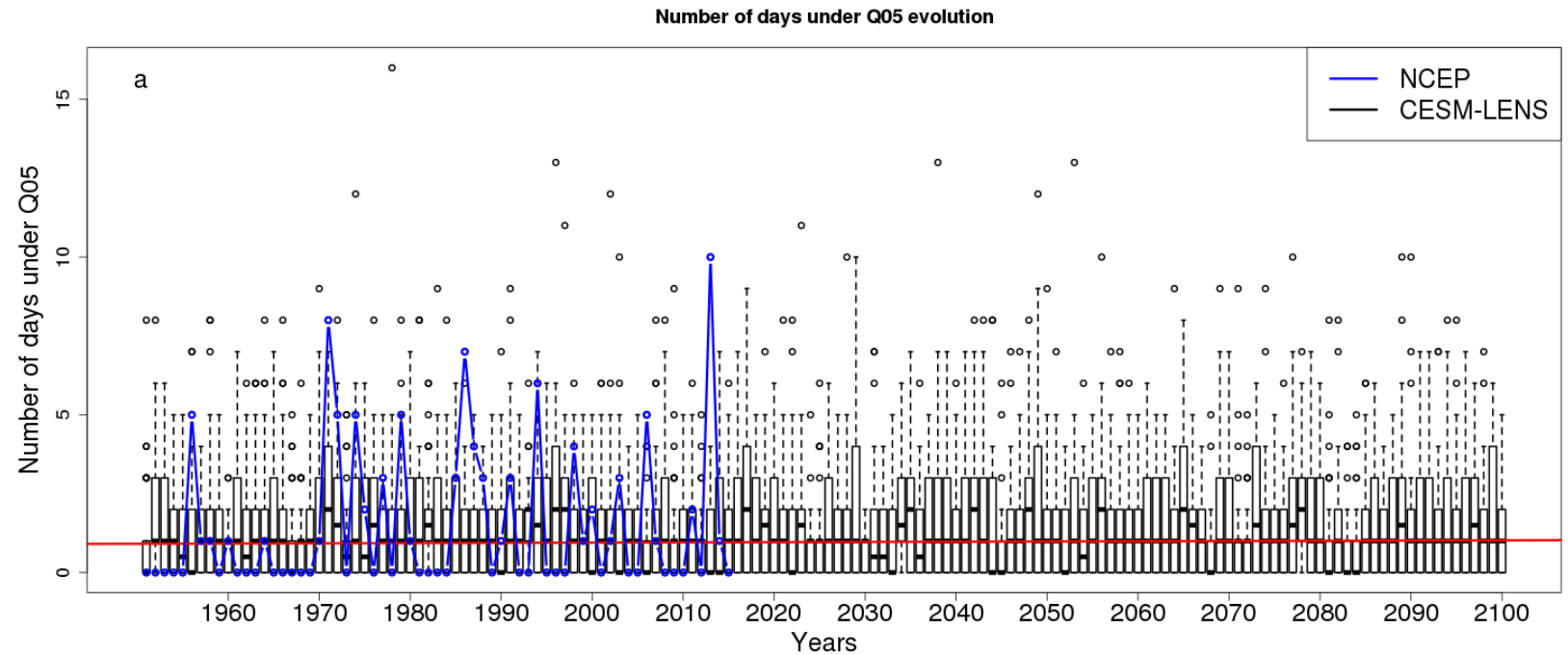

(b)

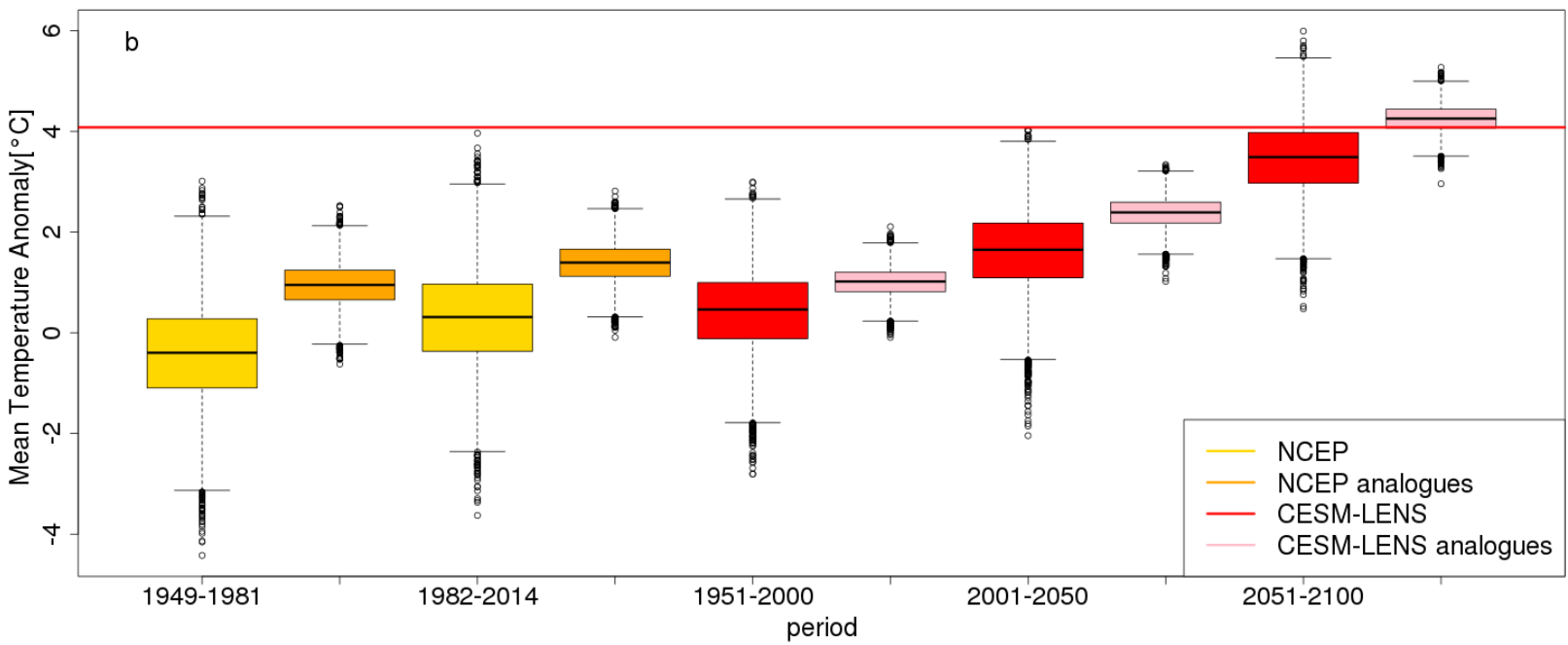

